\title{
Avaliação morfológica das membranas fetais e da placenta de Mazama gouazoubira (veado-catingueiro) de vida livre no terço inicial da gestação ${ }^{1}$
}

\author{
Amanda O. Ferreira ${ }^{2}$, Adriana C. Morini ${ }^{2}$, Phelipe O. Favaron ${ }^{2}$, Cristiane C. Passos ${ }^{2}$, \\ Danila B. Campos ${ }^{3}$, Maria A. Miglino ${ }^{2}$ e Ricardo R. Guerra ${ }^{2,3 *}$
}

\begin{abstract}
Ferreira A.O., Morini A.C., Favaron P.O., Passos C.C., Campos D.B., Miglino M.A. \& Guerra R.R. 2011. [Morphological evaluation of fetal membranes and placenta of wild life Mazama gouazoubira deer in the first third of pregnancy.] Avaliação morfológica das membranas fetais e da placenta de Mazama gouazoubira (veado-catingueiro) de vida livre no terço inicial da gestação. Pesquisa Veterinária Brasileira 31(7):631-635. Setor de Anatomia, Departamento de Cirurgia, Faculdade de Medicina Veterinária e Zootecnia, Universidade de São Paulo, Av. Prof. Dr. Orlando Marques de Paiva 87, Cidade Universitária, São Paulo 05508-270, Brazil. E-mail: ricardo@cca.ufpb.br

Mazama gouazoubira is a small-sized deer, which can be found in South America, from southern Uruguay to the north of Mato Grosso, Brazil. This study aimed to describe the fetal membranes and placenta of M. gouazoubira in the first third of pregnancy. Samples collected were macroscopically and microscopically analyzed. Uterus examination demonstrated univitelinic gestation with an embryo measuring a crown-rump length of $13 \mathrm{~mm}$. In the embryo analysis we could identify the pigmented eye, auricular hillocks, mesonephron and early metanephron, liver and its external prominence, stomach, thoracic members and buds of pelvic members. Placenta was oligocotyledonary and nine caruncles were found in the uterus. Gestational sac measured $15 \mathrm{~cm}$ in length, and, as observed in the early gestation of domestic ruminants, cotyledons could not be identified macroscopically. A weak adhesion was found between caruncles and chorioallantoic membrane (cotyledons) forming the placentomes. The chorioallantoic membrane showed a well-vascularized allantoid composed by a thin layer of cells with stretched nucleus and cytoplasm. On the other side of the membrane, the chorion was composed by cubic cells with scant cytoplasm and large-rounded nuclei, features of trophoblast cells. Involving the embryo we identified a two-layered amniotic sac. Layers could be mechanically separated and had similar morphology, showing a non-vascularized squamous epithelium. There was no yolk sac in the gestational stage of this specimen. We concluded that the placenta of M. gouazoubira is an oligocotyledonary placenta, as observed in others cervids, and that the fetal membranes showed similarities with those from other domestic ruminants, including cytological characteristics. Further studies are required in order to determine the presence of the yolk sac and its regression time.
\end{abstract}

INDEX TERMS: Yolk sac, chorioallantoic membrane, embryo, oligocotyledonary placenta, placentome.

RESUMO-- Mazama gouazoubira, o veado-catingueiro, é uma espécie de cervídeo de porte pequeno, que pode ser encontrado na América do Sul, desde o sul do Uruguai até o norte de

\footnotetext{
${ }^{1}$ Recebido em 21 de janeiro de 2011.

Aceito para publicação em 30 de março de 2011

${ }^{2}$ Departamento de Cirurgia, Setor de Anatomia dos Animais Domésticos e Silvestres, Faculdade de Medicina Veterinária e Zootecnia, Universidade de São Paulo (USP), Av. Prof. Dr. Orlando Marques de Paiva, 87, Cidade Universitária, São Paulo, SP 05508-270, Brasil.

${ }^{3}$ Departamento de Ciências Veterinárias, Centro de Ciências Agrárias, Universidade Federal da Paraíba (UFPB), Campus II, Areia, PB 58397-000, Brasil. *Autor para correspondência: ricardo@cca.ufpb.br
}

Mato Grosso, no Brasil. Este estudo teve como objetivo descrever as membranas fetais e a placenta de M. gouazoubira no terço inicial de gestação. As amostras coletadas foram analisadas macroscopicamente e microscopicamente. 0 exame do útero demonstrou uma gestação univitelina e um embrião com crown-rump de $13 \mathrm{~mm}$. Na análise do embrião pode ser observado o olho pigmentado, as saliências auriculares, o mesonefro e e metanefro em desenvolvimento, o fígado e sua proeminência externa, o estômago, os membros torácicos e os brotos dos membros pélvicos. A placenta apresentou-se oligocotiledonária e no útero puderam ser observadas nove carúnculas. 0 saco gestacional mediu $15 \mathrm{~cm}$ de comprimento e, como observado 
no início da gestação dos ruminantes domésticos, os cotilédones não puderam ser identificados macroscopicamente. Uma fraca adesão foi observada entre as carúnculas e a membrana corioalantóica (cotilédones) que formavam os placentônios. A membrana corioalantóica demonstrou um alantóide bem vascularizado composto por uma fina camada de células de núcleos e citoplasmas alongados. Na outra face da membrana, o cório foi composto por células cúbicas, de citoplasmas escassos e núcleos grandes e arredondados, características de células trofoblásticas. Envolvendo o embrião visualizou-se o saco amniótico constituído de duas camadas passíveis de separação mecânica, que apresentaram morfologia similar, sendo formadas por um epitélio pavimentoso avascular. Não foi observado saco vitelino no estágio gestacional do espécime estudado. Conclui-se que a placenta de M. gouazoubira é oligocotiledonária, como observado em outros cervídeos, e que as membranas fetais apresentam semelhanças com a de outros ruminantes, incluindo as características citológicas. Estudos adicionais são necessários para determinar a presença do saco vitelino e quando ocorre sua regressão.

TERMOS DE INDEXAÇÃO: Mazama gouazoubira, veado-catingueiro, saco vitelino, membrana corioalantóica, embrião, placenta oligocotiledonária, placentoma.

\section{INTRODUÇÃO}

Os cervídeos (família Cervidae) pertencem à ordem Artiodactyla, que se caracteriza pela presença de cascos que recobrem totalmente os pares de dedos. Existem pelo menos 38 espécies constituindo o grupo dos cervídeos (Nowak \& Paradiso 1983). No Brasil são reconhecidas 8 destas espécies: Blastocerus dichotomus, Odocoileus virginiarus, Ozotoceros bezoarticus, Mazama americana, Mazama bororo, Mazama gouazoubira, Mazama nana e Mazama nemorivaga (Cubas et al. 2007).

Os cervídeos são poliéstricos estacionais, pelo menos nas espécies de clima temperado. Sabe-se, que em clima tropical a sazonalidade não é bem definida, especialmente no gênero Mazama, em que se descreve a ocorrência de cio pós-parto no veado mateiro, demonstrando que nessa espécie a reprodução não é sazonal. Em veado campeiro, a concentração de nascimentos na primavera (setembro a novembro) no Brasil e na Argentina, indo até dezembro no Uruguai, indica certa sazonalidade. Deve ser enfatizado, no entanto, que há nascimentos durante o ano inteiro, indicando que alguns machos e fêmeas podem ser férteis por todo esse período. Em cativeiro, cervos do pantanal não apresentam sazonalidade e a gestação tem duração de 8,5 a 9 meses. Nas demais espécies de cervídeos brasileiros a duração da gestação é de aproximadamente 7 meses. 0 ciclo estral do Mazama gouazoubira (veado-catingueiro) é cerca de 21 dias e, em cervos do pantanal, por volta de 24 dias (Cubas et al. 2007).

A maioria das espécies brasileiras dá origem a somente um filhote por cria, sendo raros os casos de gêmeos, com exceção da espécie Odocoileus virginianus (veado-de-caudabranca), em que os partos gemelares são mais frequentes que os simples. Ao nascer, os filhotes possuem pintas brancas distribuídas pelo corpo, com exceção do cervo-do-pantanal (Blastocerus dichotomus), que nasce com pelagem uniforme, semelhante à do adulto. As pintas são perdidas na primeira muda de pêlos, entre 2 e 4 meses (Cubas et al. 2007).
O veado-catingueiro (M. gouazoubira) é uma espécie de porte pequeno, pesando em média $18 \mathrm{~kg}$, raramente excedendo $20 \mathrm{~kg}$ e com altura média de $50 \mathrm{~cm}$ na cernelha. A coloração geral dos indivíduos é muito variável, podendo ir do cinza escuro ao marrom avermelhado, ou até baio. A região ventral é baia, com áreas brancas na parte inferior da cauda e na face interna da orelha. As regiões submandibular e perioftálmica são mais claras, mas dificilmente chegam a ser brancas. A maioria dos indivíduos tem uma pinta branca acima dos olhos, que é inexistente em outras espécies de veados. A orelha é grande e arredondada e os chifres, presentes apenas nos machos, não são ramificados, que é uma característica de todas as espécies pertencentes aos gêneros Mazama e Pudu. Essa é a espécie de veado mais abundante na América do Sul, ocupando vários tipos de habitat, desde cerrado fechado até áreas ocupadas pela agricultura. Tem grande poder de adaptação às áreas modificadas. Ocupa desde o Sul do Uruguai até o Norte do estado do Mato Grosso no Brasil e desde a cordilheira dos Andes até o Atlântico (Cubas et al. 2007).

De maneira geral, os cervídeos neotropicais ainda são pouco estudados, seja em relação à sua taxonomia ou quanto as demais características. Essa escassez de estudos é, em grande parte, gerada pela dificuldade de acesso aos animais, que vivem em sua maioria em florestas e possuem hábitos crepusculares (Cubas et al. 2007). No entanto, observa-se que é cada vez maior os casos de atendimento destes animais por médicos veterinários. Estes atendimentos, em geral, se dão em virtude de acidentes causados pela proximidade destes animais aos centros urbanos. Além de seus predadores naturais (cachorro-do-mato e felinos, como onças), cães domésticos e a expansão urbana vem reduzindo e suprimindo as áreas domiciliares dos veados catingueiros. De acordo com Nowak (1991) os atropelamentos em estradas, seguido dos ataques por cães domésticos estão entre as maiores causas de atendimentos a veados catingueiros.

Diante do exposto, e da necessidade de maiores informações acerca das características anatômicas dos cervídeos, o objetivo deste trabalho foi descrever a morfologia das membranas fetais e da placenta em um veado-catingueiro (M. gouazoubira), a fim de fornecer subsídios para as práticas clínicas e para o manejo reprodutivo da espécie.

\section{MATERIAL E MÉTODOS}

Para este estudo foram coletadas amostras do sistema reprodutivo de uma fêmea adulta de veado-catingueiro (Mazama gouazoubira), que veio a óbito após atropelamento em rodovia na região de Guarapuava-PR. Este animal foi oriundo do SAAS (Serviço de atendimento à Animais Selvagens) da Universidade Estadual do CentroOeste (Unicentro), Guarapuava, Paraná. A fêmea pesava 19,20 kg, com $0,92 \mathrm{~cm}$ de comprimento e $0,60 \mathrm{~cm}$ de altura de cernelha.

Para a avaliação macroscópica e microscópica do sistema reprodutivo feminino foi realizada uma incisão na linha alba do animal e isolamento os órgãos abdominais. Foram tiradas fotos com câmera digital Olympus C-315 5,1 MP para catalogação e estudo.

Os fragmentos das membranas fetais e o embrião do M. gouazoubira foram fixados em solução de formaldeído tamponado a $10 \%$ e tratados em série crescente de etanol (70 a 100\%) para desidratação e xilois para diafanização, utilizando-se procedimento convencional, para posterior inclusão em Paraplast ${ }^{\circledR}$ (Leica/Germany).

Foram realizados cortes de $5 \mu \mathrm{m}$ em micrótomo semi automá- 
tico para obtenção das lâminas, as quais foram previamente silanizadas com 3-aminopropiltrietoxi-silano(APES e então desparafinizadas, coradas, analisadas e fotomicrografadas (Microscópio Olympus BX4160 acoplado a câmera Axio CAM HRc) com o software Zeiss KS 400.

Utilizaram-se as seguintes colorações histológicas: hematoxilina-eosina, tricrômico de Masson e periodic acid Schiff (PAS) (Junqueira et al. 2008).

\section{RESULTADOS}

O espécime de Mazama gouazoubira apresentou uma gestação univitelina com um embrião medindo $13 \mathrm{~mm}$ de crownrump (Fig.1C e D) alocado no corno uterino direito (Fig.1A). $\mathrm{Na}$ análise macroscópica do embrião pode ser observado o olho pigmentado, as saliências auriculares que formarão a orelha externa, a proeminência hepática, os membros torácicos e os brotos dos membros pélvicos (Fig.2B). Ao corte sagital, além do olho, puderam ser observados o fígado, o estômago, 0 mesonefro, localizado ventralmente ao longo de 12 vértebras com sua porção cranial próxima à borda do fígado, e o metanefro em desenvolvimento, localizado caudalmente ao mesonefro (Fig.2A).

A placenta apresentou-se oligocotiledonária e no exame do útero puderam ser observadas 9 carúnculas localizadas em ambos os cornos uterinos (Fig. 1B). 0 saco gestacional de uma extremidade a outra mediu $15 \mathrm{~cm}$ (Fig.1C e D) e os cotilédones não puderam ser observados macroscopicamente, sendo observada uma fraca adesão entre as carúnculas e a membrana corioalantóica que formavam os placentomas.
Na membrana corioalantóica, o alantóide apresentou-se bem vascularizado e composto por uma fina camada de células com núcleos e citoplasmas alongados. Na outra face da membrana, o cório, separado do alantóide por uma faixa de tecido conjuntivo frouxo, foi composto por células cúbicas, de citoplasmas escassos e núcleos grandes e arredondados, características de células trofoblásticas (Fig.3B).

Envolvendo o embrião visualizou-se o saco amniótico constituído de duas camadas passíveis de separação mecânica, ambas apresentando morfologias macro e microscópica semelhantes, formadas por um epitélio pavimentoso avascular (Fig. 3A). Dentro do saco amniótico encontrava-se o líquido amniótico, que era mais denso e viscoso quando comparado com o líquido alantóico. Não foi observado saco vitelino no estágio gestacional do espécime estudado.

\section{DISCUSSÃO}

Segundo Bernirschke (2007) e Hamilton et al. (1960) a placenta dos cervídeos é classificada como oligocotiledonária. No presente estudo podemos observar que a placenta do veado-catingueiro, apresentando 9 carúnculas, segue a mesma classificação, divergindo dos demais ruminantes não cervídeos, nos quais o número de placentomas é maior (Banks 1982, Samuelson 2007, Pinto et al. 2008). Bernirschke (2007), investigando a placenta de diferentes espécies de veados (nenhuma delas encontrada no Brasil), observou que estavam presentes no máximo 10 carúnculas, sendo, em média, observadas de 4 a 6 carúnculas.


Fig.1. Embrião, anexos embrionários e útero de Mazama gouazoubira. (A) Útero com embrião (ponta de seta) localizado no corno uterino direito. (B) Útero seccionado apresentando carúnculas (setas). (C) Saco gestacional (asterisco) com embrião (ponta de seta), notar a ausência de cotilédones macroscopicamente visíveis no tecido fetal. (D) Embrião (seta) com 13mm de CR (Crow-Hump). 


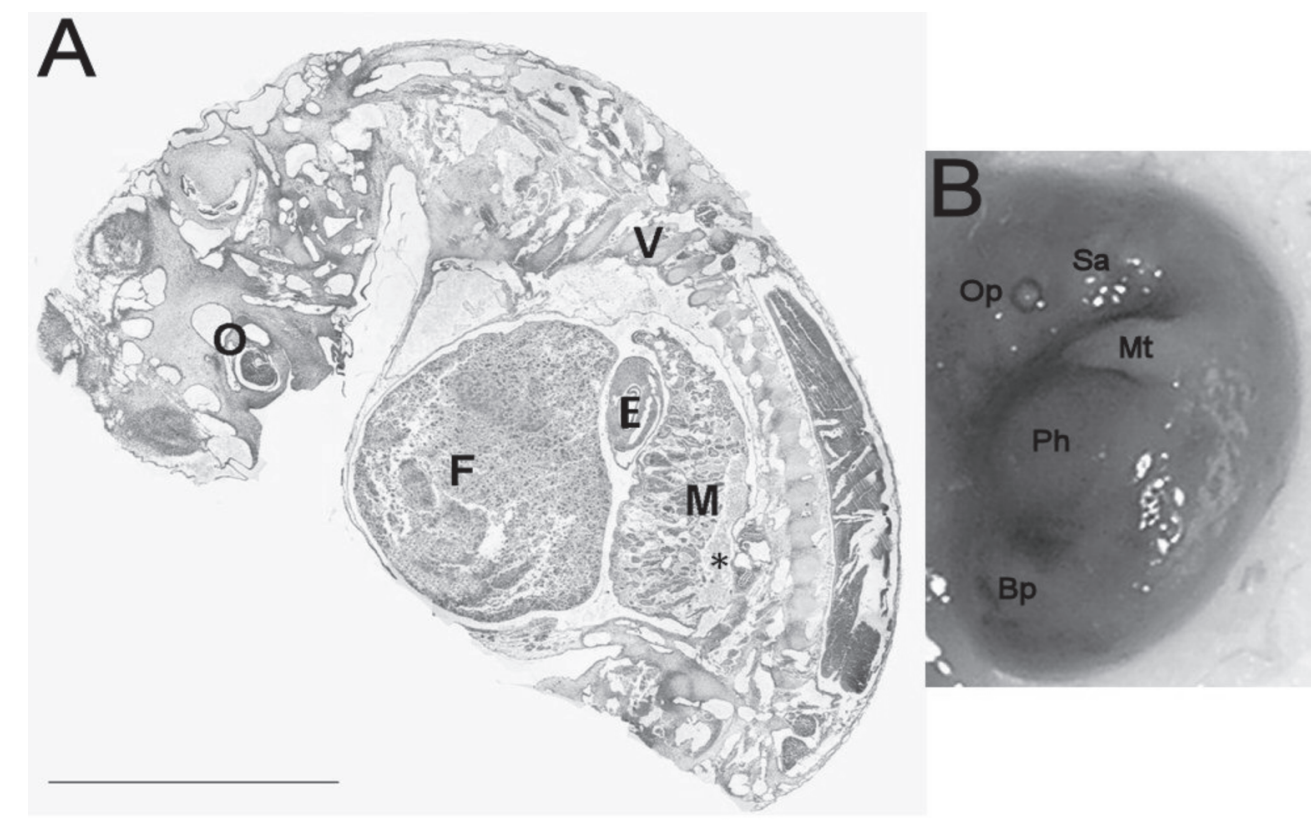

Fig.2. Embrião de Mazama gouazouabira. (A) Fotomicrografia corada com hematoxilina-eosina, evidenciando olho (O), o fígado (F), as vértebras (V), o estômago (E), o mesonefro (M) e o metanefro em desenvolvimento (asterisco). Barra: $200 \mu \mathrm{m}$. (B) Imagem fotográfica, observar o olho pigmentado (Op), as saliências auriculares (Sa), a proeminência hepática $(\mathrm{Ph})$, o membro torácico $(\mathrm{Mt})$ e o broto do membro pélvico (Bp).

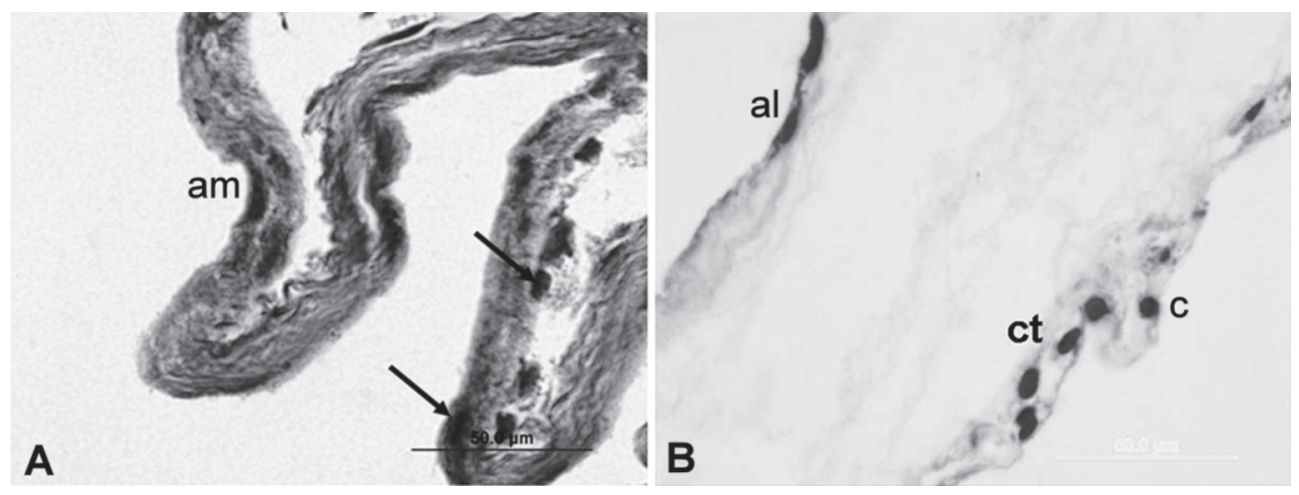

Fig.3. Membrana amniótica e corioalantóica de Mazama gouazouabira. (A) Membrana amniótica (am). As setas demonstram células fusiformes. Coloração de Periodic Acid Schiff (PAS). Barra: $50 \mu \mathrm{m}$. (B) Membrana corioalantóica. Observa-se a porção formada pelo alantóide (al), com células pavimentosas e a porção formada pelo cório (c), com células de escassos citoplasmas e núcleos ovais. Entre as mesmas há uma camada de tecido conjuntivo frouxo; (ct) células trofoblásticas. Coloração de Tricômio de Masson. Barra: 50ìm.

A implantação do espécime estudado se deu no corno direito, concordando com os achados de Chapman \& Dansie (1969), os quais relatam que a maioria das implantações nas espécies de cervídeos se dá neste corno uterino.

De acordo com Banks (1982), em relação ao grau de implantação, os cervídeos apresentam as mesmas características quando comparados aos outros ruminantes, apresentando uma placenta não-decídua, onde os tecidos maternos (carúnculas) e fetais (cotilédones) estão interdigitados e apostos. No espécime estudado, como observado em bovinos até pelo menos os 35 dias de gestação (Campos et al., dados não publicados), as áreas características de formação dos cotilédones no saco gestacional não foram observadas macroscopicamente, sendo observada uma fraca adesão entre a mem- brana corioalantóica e as carúnculas uterinas. De fato, baseado em dados relativos a outros ruminantes, o CR de $13 \mathrm{~mm}$ do embrião de veado estudado indica que a gestação era de menos de 30 dias. Segundo Chalhoub et al. (2001a,b), ovinos da raça Ideal tem um CR de $13,7 \pm 3,67 \mathrm{~mm}$ aos 29 dias de gestação e ovinos da raça Bergamácia apresentam um CR de $13,3 \pm 1,9 \mathrm{~mm}$ aos 27 dias de gestação. Consultando as tabelas de Evans \& Sack (1973) e Noden \& Lahunta (1990) para bovinos, observa-se que as informações nelas contidas também indicam a mesma fase gestacional. Adicionalmente, um CR de $12,3 \pm 1,3 \mathrm{~mm}$ foi observado em bovinos entre os dias $25 \mathrm{e}$ 30 de gestação por Assis Neto et al. (2009). Alem do CR, as características macroscópicas do embrião também indicam uma fase muito inicial da gestação, principalmente se consi- 
deramos a presença das saliências auriculares que formarão a orelha externa e o broto dos membros pélvicos. Histologicamente, também há evidências de que o embrião estudado tenha menos de 30 dias de gestação. Isso devido ao fato de que embriões bovinos entre 25 e 28 dias de gestação (CR de $10 \mathrm{~mm}$ ) possuem o mesonefro localizado ventralmente ao longo de 12 vértebras, estando a porção cranial do mesonefro próximo à borda do fígado, e a porção caudal junto ao metanefro (Cagnoto et al. 2009), o que também foi observado no embrião de M. gouazoubira estudado.

Nesta idade gestacional também não se observou o saco vitelino. 0 momento da regressão do saco vitelino em cervídeos não é descrito, entretanto Benirschke (2007) descreve a estrutura como sendo pouco desenvolvida em algumas espécies de cervídeos, e não encontrada em Pudu (Pudu pudu), outro cervídeo. Estas informações sugerem que ou o saco vitelino não esteja presente no M. gouazoubira ou sua regressão aconteça antes do que em bovinos e bubalinos, nos quais esse processo se dá por volta do 45음 dia de gestação (Banks 1982, Morini et al. 2008). Considerando que gestação do M. gouazoubira é mais curta (7 meses) do que a de bovinos e bubalinos ( 9 meses) (Morini et al. 2008), pode ser que a regressão realmente ocorra antes dos 30 dias nesta espécie.

Ao realizarmos as dissecções das membranas fetais do veado-catingueiro pudemos observar que o âmnio foi a primeira membrana a envolver o embrião, fato também verificado por outros autores (Assis 2005, Morini et al. 2008). Tanto em nosso trabalho, com o veado-catingueiro, como o realizado por Morini et al. (2008) em búfalos, não foi possível visualizar vasos sanguíneos na membrana amniótica, a qual foi formada por duas camadas celulares passiveis de separação mecânica. Em ambos os estudos, observou-se que o líquido amniótico foi mais denso e viscoso que o líquido alantóico. Em Addra (Dama gazelle), uma gazela do norte da África, apenas uma camada de células pavimentosas é encontrada constituindo a membrana amniótica (Benirschke 2007).

Os dados deste trabalho confirmam os relatos de Banks (1982) em bovinos e de Morini et al. (2008) em búfalos, os quais observaram que na evolução da gestação, a membrana alantóica une-se ao cório, participando da formação de uma placenta corioalantóica. As características citológicas do cório e do alantóide do veado-catingueiro também apresentaram similaridades com outros ruminantes domésticos. 0 cório foi constituído por uma camada de células cúbicas, dispostas em formato linear, igualmente ao descrito por Banks (1982) para bovinos e Morini et al. (2008) para bubalinos. Entretanto, estes autores descrevem que em algumas localidades esta membrana pode apresentar mais de uma camada, fato não observado em M. gouazoubira no qual apenas uma camada foi encontrada por toda extensão da membrana. A membrana alantóica em M. gouazoubira, assim como a de bovinos (Assis 2005), foi constituída por uma delgada camada de células pavimentosas.

Conclui-se que a placenta do veado-catingueiro é oligocotiledonária, como observado em outros cervídeos, e que as mem- branas fetais apresentam semelhanças com a de outros ruminantes, incluindo as características citológicas. Estudos adicionais devem ser realizados para determinar se o saco vitelino está presente na espécie e quando ocorre sua regressão.

\section{REFERÊNCIAS}

Assis A.C. 2005. Desenvolvimento placentário em bovinos obtidos por gestações naturais e por fecundação in vitro. Tese de Doutorado em Ciências, Faculdade de Medicina Veterinária e Zootecnia, USP, São Paulo, SP. $60 \mathrm{p}$.

Assis Neto A.C., Morceli J.A.B., Fonseca R., Ambrósio C.E., Pereira F.T.V. \& Miglino M.A. 2009. Biometrics evolution of the embryonic and fetal annexes in cows obtained by natural mating, at 10 to 70 days of gestation. Pesq. Vet. Bras. 29(10):859-862.

Banks W.J. 1992. Histologia Veterinária Aplicada. Editora Guanabara, São Paulo, p.467-468.

Bernirschke K. 2007. Comparative placentation <http://placentation.ucsd. edu/indxfs.html> Acesso 30 mar. 2010.

Chalhoub M., Lopes M.D., Prestes N.C. \& Ribeiro Filho A.L. 2001a. Perfil ultra-sonográfico do crescimento embrionário/fetal ovino do $21^{\circ}$ ao $41^{\circ}$ dia de gestação. Revta Bras. Saúde Prod. Anim. 2(3):65-68.

Chalhoub M., Prestes N.C., Lopes M.D., Ribeiro Filho A.L., Lopes R.M. \& Trinca L.A. 2001b. Relação entre comprimento craniocaudal e diâmetro da vesícula embrionária/fetal com idade de gestação por meio de avaliação ultra-sonográfica em ovino da raça Bergamácia. Arq. Bras. Med. Vet. Zootec. 53(1):71-77.

Chapman D.I. \& Dansie 0. 1969. Unilateral implantation in the muntjac deer. J. Zool, Lond., 159:534-536.

Cagnoto D.G., Guerra R.R., Alberto M.V., Ambrósio C.E., Santos E.J.M. \& Miglino M.A. 2009. Morfologia e desenvolvimento ultraestrutural do sistema renal de embriões bovinos com idade gestacional entre 10 e 50 dias. Ciência Rural 39(7):2154-2161.

Cubas Z.S., Silva J.C. \& Catão-Dias J.L. 2007. Tratado de Anatomia dos Animais Selvagens. Editora Roca, São Paulo. 641p.

Evans H.E. \& Sack W.O. 1973. Prenatal development of domestic and laboratory mammals: growth curves, external features and selected references. Anat. Histol. Embryol. 2:11-45.

Hamilton W.J., Harrison R.J. \& Young, B.A. 1960. Aspects of placentation in certain Cervidae. J. Anat. 94:1-23.

Junqueira L.C. \& Carneiro J. 2008. Histologia Básica. Editora Guanabara Koogan, Rio de Janeiro, p.3-4.

Pinto L.M., Ambrósio C.E., Teixeira D.G., Araújo K.P.C., Júnior J.R.K., Junior J.C.M., Rici R.E.G., Ferreira G.J.B.C., Martins D.S. \& Miglino M.A. 2008. Comportamento das células trofoblásticas gigantes na placenta de vacas Nelore (Bos indicus Linnaeus, 1758). Revta Bras. Reprod. Animal 32(2):110-121.

Morini A.C., Barbosa P.L.G., Rodrigo V., Junior J.C.M., Franciolli A.L.R., Martins D.S., Verechia F.P.T., Favaron P.O., Ambrósio C.E. \& Miglino M.A. 2008. Caracterização das membranas fetais em búfalas no terço inicial da gestação. Pesq. Vet. Bras. 28(9):437-445.

Noden D.M., De Lahunta A. 1990. Embriologia de los Animales Domésticos. Acribia, Zaragoza, Espanha. 399p. Disponível em <http://www.jurology .com/article/S0022-5347(05)60122-X/abstract> Acesso em: 14 mai. 2009. doi:10.1097/01.ju.0000161587.95033.c9.

Nowak K. 1991. Walker's Mammals of the World. $5^{\text {th }}$ ed. The Hopkins University Press, Baltimore. 1101p.

Nowak R.M. \& Paradiso J.L. 1983. Walker's Mammals of the World. $4^{\text {th }}$ ed. The Johns Hopkins University Press, Baltimore.

Samuelson D.A. 2007. Tratado de Histologia Veterinária. Elsevier, Rio de Janeiro. $527 p$ 